\title{
Function of the Basal Ganglia as Revealed by Cognitive and Motor Disorders in Parkinson's Disease
}

\author{
C.D. Marsden
}

\begin{abstract}
Early Parkinson's disease is taken to be the best human model of disordered basal ganglia function. An experimental study in Parkinsonians with swings in motor response to drug treatment suggests that general cognition is not controlled by dopamine mediated striatal activity. The variety of motor disorders in Parkinson's disease cannot be explained by simple concepts. Although Parkinsonians cannot execute fast ballistic movements, an experimental study shows that they can adopt a predictive motor control strategy. It is argued that simple motor programs are not grossly disturbed in Parkinson's disease. It is concluded that Parkinsonians cannot automatically execute learned motor plans.
\end{abstract}

RÉSUMÉ: La maladie de Parkinson dans ses débuts est le meilleur modèle d'un trouble fonctionnel des noyaux gris centraux. L'étude de patients ayant des variations motrices importantes secondaires au traitement médical suggère que les fonctions cognitives ne sont pas modéré par l'activité de la dopamine striatale. la variété des troubles moteurs dans la maladie de Parkinson ne peut être expliquée par des concepts simples. Même si les Parkinsoniens ne peuvent exécuter les mouvements ballistiques rapides, ils sont encore capables d'adopter une stratégie prédictive du contrôle moteur. Donc les programmes moteurs simples ne sont pas grossièrement atteints dans la maladie de Parkinson, mais les patients ne peuvent exécuter automatiquement les plans moteurs appris.

Can. J. Neurol. Sci. 1984: 11:129-135

There is considerable debate on the functions of the basal ganglia. Two areas arouse the greatest controversy.

A) Are the basal ganglia concerned solely with the control of movement, albeit in a complex way? Or are the basal ganglia involved not only with movement, but also with those other complex brain functions loosely described as cognitive?

B) If the basal ganglia are primarily involved in motor behaviour, what aspect of motor action do they influence?

Neither question is resolved. Many lines of evidence can be brought to bear on the discussion (Table 1), but here I will concentrate on the clinical data.

Any theory of basal ganglia action must accommodate the observed effects of basal ganglia damage in man. But there are major problems in interpreting the significance of these data. The difficulty is that human pathology is rarely confined to basal ganglia structures. Lesions due to tumor, trauma or vascular disease usually trangress the confines of the basal ganglia, so that the symptoms and signs that they produce cannot be attributed with confidence solely to basal ganglia damage. Degenerative diseases, such as Parkinson's disease and Huntington's disease, also involve structures other than the basal ganglia, although the brunt of their attack falls on the functions of the striopallidal complex. These problems are highlighted in Table 2.

Another problem is that the basal ganglia are not uniform. The caudate nucleus, putamen and ventral striatum (including the nucleus accumbens and olfactory tubercle) receive different inputs and project to different zones of the pallidum, which may themselves project to different areas of the thalamus and frontal

\begin{tabular}{|c|c|c|}
\hline Source & Question & Answer \\
\hline \multirow[t]{2}{*}{ Anatomical } & $\begin{array}{l}\text { What information has the } \\
\text { basal ganglia to work on? }\end{array}$ & $\begin{array}{l}\text { Inputs to the basal } \\
\text { ganglia }\end{array}$ \\
\hline & $\begin{array}{l}\text { Where does it distribute } \\
\text { its message? }\end{array}$ & $\begin{array}{l}\text { Outputs of the basal } \\
\text { ganglia }\end{array}$ \\
\hline \multirow[t]{3}{*}{ Physiological } & $\begin{array}{l}\text { To what do the basal } \\
\text { ganglia respond? }\end{array}$ & $\begin{array}{l}\text { Behaviour of striatal } \\
\text { neurons }\end{array}$ \\
\hline & $\begin{array}{l}\text { How is the output message } \\
\text { of the basal ganglia } \\
\text { coded? }\end{array}$ & $\begin{array}{l}\text { Behaviour of } \\
\text { pallidal and } \\
\text { reticulata neurons }\end{array}$ \\
\hline & $\begin{array}{l}\text { What effect does that } \\
\text { message have? }\end{array}$ & $\begin{array}{l}\text { Behaviour of } \\
\text { neurons in } \\
\text { brainstem, } \\
\text { thalamus, } \\
\text { premotor and } \\
\text { frontal cortex }\end{array}$ \\
\hline Behavioural & $\begin{array}{l}\text { What is the effect of } \\
\text { damage or pharma- } \\
\text { cological manipulation of } \\
\text { the basal ganglia }\end{array}$ & $\begin{array}{l}\text { Animal experiments } \\
\text { Human pathology }\end{array}$ \\
\hline
\end{tabular}

cortex. Basal ganglia diseases may preferentially attack specific regions of these structures. Thus, the major deficiency of dopamine in Parkinson's disease is in the motor striatum (the putamen), although the caudate nucleus and ventral striatum are also affected to a lesser degree. In contrast, the brunt of Huntington's disease falls on the caudate nucleus and the putamen 


\begin{tabular}{|c|c|c|}
\hline $\begin{array}{l}\text { Common Basal } \\
\text { Ganglia Disease } \\
\end{array}$ & $\begin{array}{c}\text { Core } \\
\text { Pathology } \\
\end{array}$ & $\begin{array}{l}\text { Additional } \\
\text { Pathology } \\
\end{array}$ \\
\hline Parkinson's disease & $\begin{array}{l}\text { Degeneration of substantia } \\
\text { nigra compacta and loss } \\
\text { of striatal dopamine }\end{array}$ & $\begin{array}{l}\text { Mesocortical } \\
\text { dopamine } \\
\text { deficiency, } \\
\text { noradrenaline } \\
\text { deficiency, } \\
\text { cortical } \\
\text { acetylcholine loss }\end{array}$ \\
\hline $\begin{array}{l}\text { Huntington's } \\
\text { disease }\end{array}$ & Degeneration of striatum & $\begin{array}{l}\text { Cortical and } \\
\text { thalamic atrophy }\end{array}$ \\
\hline Hemiballism & $\begin{array}{l}\text { Lesion of subthalamic } \\
\text { nucleus }\end{array}$ & $\begin{array}{l}\text { Often the lesion is } \\
\text { elsewhere }\end{array}$ \\
\hline Torsion dystonia & $\begin{array}{l}\text { Often not known, or } \\
\text { multiple/diffuse }\end{array}$ & \\
\hline Tics & Not known & \\
\hline
\end{tabular}

with the ventral striatum being relatively spared. Not only may these differences contribute to the dissimilar motor disorders in the two conditions, but they invalidate using either disease alone as a general model of abnormal function of the human basal ganglia.

However, if one is forced to decide which human illness is closest to providing a picture of abnormal basal ganglia function in man, I opt for Parkinson's disease. Although the putamen is affected more than other parts, there is still a profound depletion of dopamine in the caudate nucleus and in the ventral striatum. Furthermore, unlike Huntington's disease, the cortical changes in Parkinson's disease are likely to occur later in the illness. Parkinson's disease is not a perfect model, but it may be the most informative that we have.

\section{Cognitive Changes in Parkinson's Disease}

Any discussion of cognitive abnormalities in Parkinson's disease must take into account the knowledge that it is not a static illness. Despite modern treatment, mainly with dopamine agonists such as levodopa, the underlying pathology of the disease progresses and approximately a third of patients sooner or later exhibit clear evidence of selective cognitive deficit or frank global dementia (see Mayeux and Stern, 1983 for a review of this topic). Any cross-sectional survey of a cohort of patients with Parkinson's disease therefore will inevitably show an average decline in cognitive funcitons, when compared to normal control subjects. However, this does not prove that the basal ganglia are involved in general or specific cognition. Such a sample inevitably includes patients with the advanced pathology of the illness, including cerebral cortical changes. Ruberg and her colleagues (1982) and Perry et al. (1983) have demonstrated clear deficiencies of markers of cerebral cholinergic neurones in patients with Parkinson's disease who are demented.

The crucial question is whether patients with Parkinson's disease inevitably exhibit specific or general cognitive abnormalities. To show that some do is not conclusive evidence that the basal ganglia are concerned with cognition as well as complex motor control.

\section{Intellectual Ability in Swinging Parkinsonians}

To study this point we (Brown et al., 1984) have turned to a specific group of patients with Parkinson's disease, namely those who have responded well to levodopa treatment, but who have developed severe fluctuations (swings) in their motor capacities while on therapy. Such patients undoubtedly have severe Parkinson's disease. When levodopa does not work, or when levodopa is withdrawn, they are grossly incapacitated, many being chair or bed-bound. In contrast, when the drug works, these patient are normally mobile, albeit often with dyskinesias as a side effect. Such swings in motor performance from good to bad are levodopa dependent, so can be presumed to represent the extremes of dopamine action in the striatum. When good and mobile, the dopamine derived from levodopa presumably is allowing normal striatal function. When bad and immobile, lack of adequate dopamine formation presumably inactivates the striatum. This interpretation is reinforced by the demonstration that continuous intravenous levodopa infusions can abolish all such swings in performance (see, for example, Quinn et al., 1982).

The question we have addressed is what happens to cognitive function in these two extremes of motor ability, representing normal and abnormal dopamine-mediated striatal action.

We studied 16 patients exhibiting such behaviour (Table 3 ). They were matched for age, sex, education and intellectual ability with 25 control subjects. A test of general intellectual capacity (the modified Alice Heim test) was chosen as requiring minimal motor capability, so as to avoid the contaminating effects of changes in motor performance. Two forms of the modified Alice Heim test, validated for test-retest reliability, were administered to the patients when good and mobile, and when bad and immobile. The two forms of the test also were administered to the control subjects on two separate occasions. The order of presentation of the two forms of the test was randomized. No time limits were set, but the time taken to complete the test was recorded.

The modified Alice Heim test examines general intellectual capacity in three main spheres, verbal, visuo-spatial and numerical reasoning. It involves answering a series of 79 questions, each of which has the format of selecting the correct response from a series of choice, (for details of the form of the test see Brown et al., 1984). In addition, each subject completed a self-rating questionnaire exploring mood and alertness prior to and after completing the modified Alice Heim test.

The results are summarized in Table 4 . Although the Parkinsonian patients when mobile did not differ from control subjects in their adjusted scores on the Verbal Scale of the Weschler

\begin{tabular}{lcc}
\hline $\begin{array}{l}\text { Table 3: Characteristics of Patients with Fluctuating Parkinson's Disease } \\
\text { and Control Subjects }\end{array}$ & $\begin{array}{c}\text { Parkinson's Disease } \\
\mathrm{n}=16\end{array}$ & $\begin{array}{c}\text { Controls } \\
\mathrm{n}=25\end{array}$ \\
\hline \hline & $\begin{array}{c}56.3 \mathrm{yr} \\
( \pm 9.8)\end{array}$ & $\begin{array}{c}57.6 \\
( \pm 12.9)\end{array}$ \\
\hline Age & $45.1 \mathrm{yr}$ \\
Age at onset of illness & $( \pm 9.3)$ & - \\
Duration of & $9 \mathrm{yr}$ & - \\
levodopa therapy & $( \pm 2.5)$ & 10.2 \\
Education & $11.8 \mathrm{yr}$ & $( \pm 2.7)$ \\
Verbal IQ & $( \pm 2.9)$ & 121.1 \\
& 116.6 & $( \pm 11.0)$ \\
\hline
\end{tabular}

Means \pm 1 SD are shown 
Table 4: Changes in Cognitive Performance in Parkinsonian's when Mobile and Immobile, Compared to Control Subjects

\begin{tabular}{lccc}
\hline \hline & $\begin{array}{c}\text { Controls } \\
\mathrm{n}=25\end{array}$ & \multicolumn{2}{c}{$\begin{array}{c}\text { Parkinsonians } \\
\mathrm{n}=16\end{array}$} \\
\hline & & Mobile & Immobile \\
\hline Motor capacity! & Normal & 13.2 & $55.9+$ \\
& & $( \pm 6.0)$ & $( \pm 15.9)$ \\
Time required to complete & 1267 & 1254 & 1086 \\
MAHT (seconds) & $( \pm 555)$ & $( \pm 473)$ & $( \pm 548)$ \\
& & & \\
Accuracy of response ${ }^{2}$ to & 75.8 & $67.4^{*}$ & $61.3^{*}+$ \\
MAHT (per cent) & $( \pm 10.0)$ & $( \pm 12.7)$ & $( \pm 13.4)$ \\
& 43.3 & $51.1^{*}$ & $58.9^{*}+$ \\
Affect-arousal score & $( \pm 8.3)$ & $( \pm 10.5)$ & $( \pm 15.9)$
\end{tabular}

Means \pm 1 SD are shown. MAHT $=$ Modified Alice Heim Test

1. Motor capacity was measured by the King's College Hospital Parkinson's Disease Rating Scale. $0=$ normal, $117=$ maximum disability. As a general guide, a score of 10 or less indicates minimal disability with normal mobility; a score of 50 or more indicates severe disability with the subject likely to be chair or bed-bound.

2. The accuracy of the response is given as the number of correct answers as a percentage of the total number of 79 questions. There was no statistically significant difference between the accuracy of the control subjects in the two tests administered, so their results are combined.

3. The affect-arousal score is an arbitrary index derived from selfrating on analogue scale of the subject's perception of their position between two extremes of 13 items, such as "sad" vs. "happy", and excluded items involving motor skills.

* Parkinsonians statistically different from control subjects; $p<0.05$ or less.

+ Parkinsonians when immobile, statistically different from when mobile; $p<0.05$ or less.

Adult Intelligence Scale, they did exhibit slightly less success in completing the modified Alice Heim test. They gave only $67 \%$ accurate answers compared to the controls who achieved a $76 \%$ accuracy. When immobile the Parkinsonians were less accurate than when mobile ( $61 \%$ vs $67 \%)$. However, these mean figures hide a crucial point (Table 5). $72 \%$ of control subjects did not differ in their performance on the two tests by more than 4 points, and $92 \%$ did not differ by more than 8 points. 44\% of Parkinsonians did not differ when mobile compared with immobile by more than 4 points, and $69 \%$ did not differ by more than 8 points. In other words, at a conservative estimate, a half of the Parkinsonians did not change in their intellectual performance between the two extremes of motor capacity, and near to two-thirds showed a change that might be within the range of what could occur in normal subject.

The reasons for the deterioration in intellectual performance that occurred in some patients with Parkinson's disease when mobile and immobile are of interest. It was not because they took longer to do the test, rather the opposite. Nor was there a correlation between the extent of their change in intellectual ability and their change in motor capacity. Statistical analysis revealed that the major correlation was with changes in their mood and alertness. When mood and alertness deteriorated, accuracy in the modified Alice Heim test failed.

The major conclusion from this study, for the purpose of the present discussion, is that patients with severe Parkinson's
Table 5: Difference in Accuracy Scores in the Modified Alice Heim Test on Two Occasions in Control Subjects Compared with Parkinsonians when Mobile and Immobile

\begin{tabular}{lcc}
\hline \hline Change in Score & $\begin{array}{c}\text { Control Subjects } \\
\text { (Two tests) } \\
(\mathbf{n}=25)\end{array}$ & $\begin{array}{c}\text { Parkinsonians } \\
\text { (mobile and } \\
\text { immobile) } \\
\text { (n = 16) }\end{array}$ \\
\hline 4 or less points & 18 & 7 \\
5 to 8 points & 5 & 4 \\
9 to 12 points & 2 & 2 \\
greater than 12 points & 0 & 3 \\
\hline
\end{tabular}

disease may show no obvious deterioration in their general intellectual abilities, even when they become grossly immobile. How can this be explained if the basal ganglia are involved in general cognitive ability?

It could be argued that there is a specific localised striatal dysfunction in these Parkinsonian patients. Indeed, attention has been drawn to the biochemical evidence that the motor striatum (putamen) is most affected in this illness. This possibility cannot be ruled out. However, these patients all had advanced Parkinson's disease, as shown by their great motor incapacity when levodopa did not work. The biochemical evidence suggests that at this stage of the illness there was likely to be severe dopamine depletion not only in the putamen, but also in the caudate nucleus and ventral striatum.

Another valid criticism is that the modified Alice Heim test may not have examined specific cognitive functions undertaken by the basal ganglia. Certainly this could be the case. For example, cognitive behaviours that seem to decline even in early untreated Parkinson's disease are the ability to undertake the Wisconsin Card Sorting Test and Benton's Word Fluency Test (Lees and Smith, 1983), which also are impaired in frontal lobe disease. This possibility should be the subject of further studies.

\section{What is the Critical Motor Defect in Parkinson's Disease?}

The classical motor features of Parkinson's disease are tremor, rigidity, changes in posture, and loss of movement (akinesia) or slowness of movement (bradykinesia). Which of these are to be taken as the critical abnormalities of the illness relevant to the functions of the basal ganglia?

Not every patient with Parkinson's disease exhibits the classical $5 \mathrm{~Hz}$ rest tremor, or even the other common $6-7 \mathrm{~Hz}$ postural tremor. There also are other reasons for considering Parkinsonian tremor as not the most significant sign of basal ganglia damage in that illness. It is possible to provoke a mimic of Parkinsonian tremor in the experimental monkey by placing a lesion in the ventral tegmental area (Poirier et al., 1975). However, this lesion must involve not only the nigrostriatal dopaminergic pathway, but also the ascending cerebello-rubro-thalamic projections. A lesion of either alone is insufficient. An animal with a lesion of the cerebello-rubro-thalamic system, which by itself does not cause such tremor, will develop tremor if given drugs that antagonise dopaminergic function. The conclusion from these experiments must be that damage in addition to that to basal ganglia is required for Parkinsonian tremor to be manifest, at least in non-human primates. In addition, tremor is a "positive" sign in the terms introduced by Hughlings Jackson, who pointed 
out that such "positive" signs were due to release or disinhibition of other parts of the nervous system.

Rigidity is a near universal "positive" sign of Parkinsonism, but it also may be a consequence of release of remote mechanisms normally suppressed by basal ganglia activity. Thus, one mechanism of Parkinsonian rigidity appears to be release of enhanced long-latency stretch reflexes, which themselves do not employ pathways traversing the basal ganglia (Lee and Tatton, 1975; Tatton and Lee, 1975; Rothwell et al., 1983). This is analagous to spasticity, in which damage to cortico-motoneurone pathways causes release of spinal mechanisms of enhanced stretch reflex activity. In both situations, rigidity and spasticity, the change in muscle tone is a sign of damage to specific regions, but it is caused by over-activity of other intact mechanisms.

The significance of postural instability is more difficult to analyse. There is no doubt that loss of postural adjustments, righting relfexes, and protective reactions is one of the cardinal signs of Parkinson's disease (Purdon Martin, 1967). However, postural instability, generally, is a sign of advanced Parkinsonism. In the earlier stages of the illness, when akinesia, tremor and rigidity are quite evident, postural stability often is maintained. This can be interpreted in two ways. Either the damage to basal ganglia function is not sufficient at that stage to compromise the postural functions of these structures. Or, the advent of additional pathology in the advanced state of the disease is required before postural instability becomes manifest. It is difficult to decide between these two possiblities. However, to err on the side of conservatism, one may choose to view the postural changes of Parkinsonism as not necessarily a sign of pure basal ganglia dyfunction. Certainly one must admit that this is not the view of some authorities, such as Purdon Martin himself, who has placed great weight on the role of the basal ganglia in regulating posture. However, there are other reasons, to be discussed later, which suggest that basal gangla function is not confined to postural control.

This leaves akinesia and bradykinesia as the key motor abnormalities indicative of abnormal basal ganglia function in Parkinson's disease, a view sponsored forceably by the late Denny-Brown (1968). If this analysis is correct, then it is on these "negative" manifestations that attention should be focused as the most important motor disorders caused by the relatively selective basal ganglia damage in early Parkinson's disease.

\section{Disorders of Simple Movements in Parkinson's Disease}

Both simple and complex movements are disrupted in Parkinson's disease (Table 6). By simple movements, I refer to single motor actions such as moving a limb from one point to another.

In Parkinson's disease there often is a delay in starting a movement and the action is carried out too slowly. Thus reaction time and movement time are prolonged, albeit to variable degrees (Wilson, 1925; Evarts et al., 1981). The initiation of movement is sometimes completely "stalled" in Parkinson's disease, as when such patients "freeze". "Freezing" may affect gait, arm movement or speech, and often is precipitated by sensory stimuli, and unlocked by other sensory stimuli.

All forms of simple movement are affected. Thus, the actions of both proximal and distal muscles are abnormal, both fast and slow movements may be disrupted, and few parts of the body are spared (see Marsden, 1984 for review).

\begin{tabular}{|c|c|}
\hline \multicolumn{2}{|l|}{ Simple Movements } \\
\hline Delay in initiation & $\begin{array}{l}\text { (Wilson, 1925; Flowers, 1976: } \\
\text { Heilman et al., 1976) }\end{array}$ \\
\hline Slowness in execution & (Evarts et al., 1981) \\
\hline $\begin{array}{l}\text { Inadequate initial agonist burst, } \\
\text { and need for repetitive bursts, } \\
\text { in fast movements }\end{array}$ & (Hallett \& Khoshbin, 1980) \\
\hline $\begin{array}{l}\text { Slowness to execute corrective } \\
\text { action }\end{array}$ & (Angel et al., 1970) \\
\hline \multicolumn{2}{|l|}{ Complex Movements } \\
\hline $\begin{array}{l}\text { Slowness and fatigue of repetitive } \\
\text { action }\end{array}$ & (Wilson, 1925; Schwab et al., 1959 \\
\hline $\begin{array}{l}\text { Inability to execute concurrent } \\
\text { actions }\end{array}$ & $\begin{array}{l}\text { (Schwab et al., 1954: Schwab \& } \\
\text { Talland, 1964; Horne, 1973) }\end{array}$ \\
\hline $\begin{array}{l}\text { Inability to execute sequential } \\
\text { actions. }\end{array}$ & (Schwab et al., 1954) \\
\hline
\end{tabular}

Following Kornhuber's (1971) influential article, it became fashionable to consider that the basal ganglia were concerned with the control of slow ramp movements. Clinical observation, however, clearly indicates that patients with Parkinson's disease have profound difficulty with fast ballistic movement. Flowers (1976), for instance, has demonstrated the Parkinsonian patient's inability to manually track step changes in position presented visually. The Parkinsonian is unable to achieve the required velocity because of a breakdown of the normal control of ballistic activation of muscles. Hallett and Khoshbin (1980) have shown that the Parkinsonian patient activates agonist and antagonist muscles in the correct time sequence, but cannot deliver sufficient EMG activity in the initial ballistic agonist burst to achieve the required rate of force increase, nor the required level of force to attain a large fast movement. The patient with Parkinson's disease achieves the point of aim by a series of small ballistic bursts which, summed together, jerkily drag the limb to the required position.

\section{Predictive Motor Action in Parkinson's Disease}

Fast ballistic movements require predictive action " in that - (normal) subjects operate with a repetoire of predetermined movements or movement sequences, predictively selected and, within limits, producing a predictable effect" (Flowers, 1976). Since patients with Parkinson's disease cannot make accurate fast ballistic movements, Flowers concluded that patients with Parkinson's disease "have a longer reaction time than normal, both in initiating and stopping (or correcting) movements, and they have less facility for producing appropriately the fast preprogrammed movements which in normals overcome the limitations of reaction time". As a result, he suggested that "A loss of prediction in the selection or performance of movements will make it difficult for these patients to do anything in the way of 'skilled' movement, wherever skill involves the use of automatic predetermined actions and sequences of action to bypass the reaction time bottleneck on performance, even where such movements are themselves relatively gross as far as dexterity is concerned. Where movements are unpredictable, also, large amplitude and fast movements will tend to go wildly astray within the reaction time period if the subject attempts them, 
and there will be a tendency to perform all action at a slow and steady pace so that a reasonable degree of control may be maintained".

If this hypothesis is correct, it could be argued that the basal ganglia are responsible for computing and/or delivering the motor programs required for predictive motor action.

In subsequent studies, Flowers (1978 a \& b) went on to examine this hypothesis in a series of pursuit tracking tasks using a manual joystick coupled to a visual display. He showed the Parkinsonians were less accurate than control subjects at tracking a known sine wave, and followed the target with a greater tracking lag. Parkinsonians showed little or no improvement when tracking a known sine wave compared with an irregular wave-form generated by a "noise" signal (Flowers 1982a). He concluded that Parkinsonians "have difficulty in generating continuous regular movements spontaneously, and seem to lack a dynamic 'internal model' of their own movements from which to control them predictively". In a further series of experiments (Flowers, 1982b), Parkinsonians were found less accurate in following a known tracking pattern if the target was made to disappear temporarily, a strategy also employed by Stern et al. (1982). Flowers again interpreted this as evidence that Parkinsonians have difficulty in utilizing prediction in their motor control. However, an alternative view is that these results indicate that patients with Parkinson's disease cannot accurately and continuously sequence motor commands, particularly if suddenly disturbed by unusual external stimuli such as disappearance of the tracking spot.

Day and I have also examined whether patients with Parkinson's disease are unable to utilize predictive motor control. We devised a method to examine the normal individual's capacity to employ predictive action in a visually-guided motor task (Day and Marsden, 1982). Twenty-two subject performed a series of 150 visual tracking tasks each $5 \mathrm{sec}$. long. The subject was asked to execute flexion and extension movement of the elbow, the position of which was sensed by a potentiometer whose output was displayed on a cathode ray oscilloscope. The subject was asked to move the elbow so as to track a second target spot displayed on the oscilloscope. The target-movement patterns used for the first 50 trials were all different, but for the remaining 100 trials they were identical. Subjects, however, were not informed of the repetition until the final 50 trials. When the task was made repetitive, even though the subjects were unaware of the repetition, some learning occurred as evidenced by a small progressive reduction in tracking error, although tracking lag remained above the mean reaction-time. Once subjects were aware of the repetition, tracking lags often fell to zero or even negative values and tracking error dropped even further (Fig. 1). It is argued that the former learning is confined to subconscious improvement in the intermittent response to visual inspection of tracking error, whereas the latter is achieved by adopting a truly predictive mode of tracking. Further experiments were devised to evaluate the role of visual information in movement control when using the predictive strategy. The main finding was that even when moving predictively, visual information was used to regulate motor output, largely to modify the timing of the predictive response to synchronize with the stimulus.

We then adapted the task for use in patients with Parkinson's disease. This involved reducing the speed of change of the target movement so as to allow for the slower movement of Parkinsonians. Twenty-five unselected patients with Parkinson's

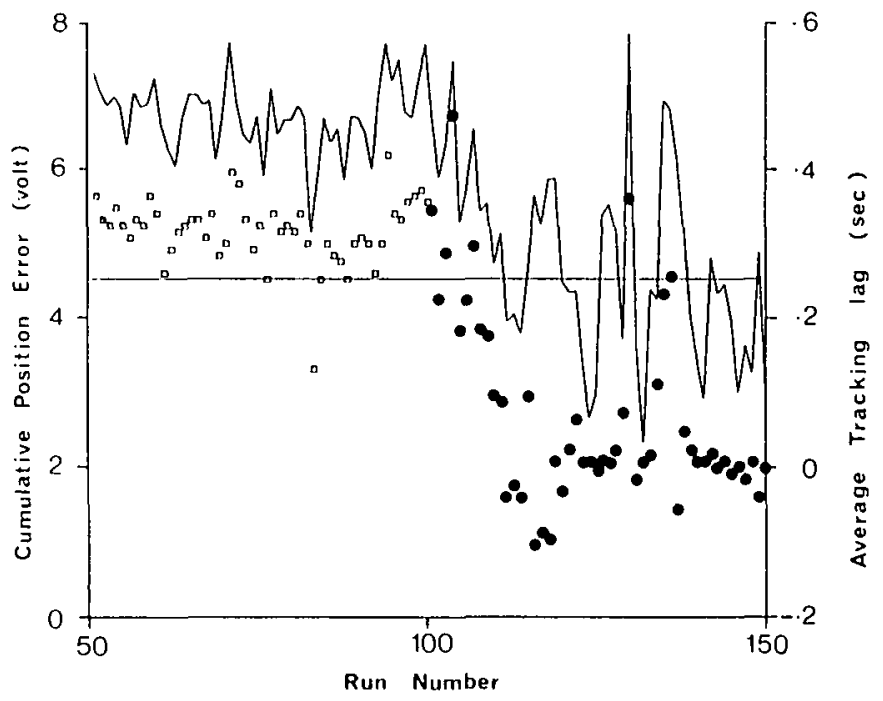

Figure I - Normal tracking performance in a visually guided task. The subject flexed the elbow, whose position was displayed on a cathode ray tube, so as to follow a second target spot. Each run. from 50 to 150 , was of a similar pattern lasting 5 seconds. Up till run 50, the subject was unaware that the same pattern was occurring, but at run 50 he was told that the pattern was repetitive. Tracking error (solid line) thereafter improved, and tracking lag (squares and solid dots) dramatically dropped. Tracking lag prior to knowing that the pattern repeated itself (squares) was close to or greater than visual reaction time (shown as the horizontal solid line). In other words, the subject followed the target spot by visual matching of arm position. When the subject knew that the pattern repeated itself, tracking lag (solid dots) dropped rapidly to zero, indicating the adoption of a predictive strategy.

disease were examined; they included patients with Parkinson's disease were examined; they included those with all degrees of duration and severity of the illness, and no attempt was made to exclude individuals with cognitive defect or dementia. Nevertheless, 12 of the 25 were capable of adopting a predictive nature of the final section of the task, as shown by a reduction of tracking error and of tracking lag well below visual reaction time.

In a further experiment (Day and Marsden, in preparation), 5 patients with moderately severe Parkinson's disease and intact general cognition were selected for study both when mobile on effective drug treatment, and when akinetic when drugs were withdrawn. All 5 patients were capable of adopting the predictive motor control strategy both when mobile and when akinetic.

From these observations we conclude that a failure of predictive motor action is not an inevitable feature of Parkinson's disease. It is unlikely that the basal ganglia are concerned solely with this aspect of motor function.

\section{Breakdown of the Motor Plan in Parkinson's Disease}

From what has been said, no one defect in simple motor action satisfies as a complete explanation for the disorders of movement that occur in Parkinson's disease. Indeed, the Parkinsonian characteristically has the greatest difficulty in undertaking complex motor actions.

Wilson (1925) and Schwab et al. (1959) were impressed by the inability of patients with Parkinson's disease to sustain repetitive motor action. Indeed, this is one of the best bedside indicators of Parkinsonian akinesia. The patient cannot continue to rapidly open or close the hand, or approximate the ball of the thumb to that of the index finger, or tap the foot on the ground. 
The movement progressively decreases in amplitude and slows in speed, until it may cease. Schwab et al. (1954) also demonstrated the inability of Parkinsonian's to undertake two simple motor acts at the same time, even though they could perform them individually. Schwab and Talland (1964) and Horne (1973) confirmed this observation with more complex simultaneous manual tasks. Schwab et al. (1954) also remarked upon the ability of Parkinsonians to carry out an uninterrupted sequence of motor actions, a defect subsequently explored experimentally by Flowers (1978 a \& b) and Stern et al. (1983). Clearly, patients with Parkinson's disease are unable to execute both simple and complex motor behaviours. Indeed, the general conclusion is that the greater the complexity of the task, the more is the Parkinsonian impaired.

The successful completion of a motor behaviour involves a series of decisions and actions. Central to motor skill is the concept of the motor strategy or the motor plan (Marsden, 1982). To achieve an objective of movement, the subject requires to assemble the series of motor programs required to move in the required direction, at the necessary time, and at the right pace. The individual components of the motor plan may be termed motor programs, each of which involves the activation of appropriate agonists and synergists with adjustment of antagonists and postural fixators. Such motor programs comprise "a set of muscle commands that are structured before a movement sequence begins, and that allows the entire sequence to be carried out uninfluenced by peripheral feed-back' (Keele, 1968). That humans are capable of delivering such motor programs is well illustrated by the extensive range of both simple and complex motor acts that can be executed by a de-afferented man (Rothwell et al., 1982). The motor plan involves the selection, sequencing and delivery of the correct collection of motor programs required to achieve the desired motor behaviour. Is the motor plan deficient in Parkinson's disease?

The Parkinsonian cannot deliver the correct force command to the agonist muscle in a fast movement (Hallett and Khoshbin, 1980). But, the correct agonist is selected, and the normal pattern of antagonist command is delivered. In other words, the Parkinsonian, when he moves, moves in the right direction with the correct muscle(s) (see also Angel et al., 1970). The Parkinsonian also makes proper use of synergists. On the basis of extensive clinical observation, Wilson (1925) concluded that synergistic actions are "executed normally by Parkinsonians, that is to say, the movements follow normal physiological lines and are neither lost nor perverted".

These commonplace clinical observations suggest that the initial selection of the subunits of the motor plan, the motor programs, is preserved in basal ganglia disease. Indeed, the experiments illustrating predictive motor action described above illustrate that the Parkinsonian is capable of storing appropriate learned motor programs for delivery in advance of visual feedback.

What then goes wrong in Parkinson's disease? Elsewhere, I have suggested that an essential defect is the inability of the Parkinsonian to automatically execute learned motor plans (Marsden, 1982). The suggestion is that the motor function of the basal ganglia is to automatically and subconciously run the sequence of motor programs that comprise a motor plan. The programs themselves may be learned and stored elsewhere in the brain, and perhaps are assembled into the coherent plan in the pre-motor and frontal areas. But the initiation and automatic execution of the sequence of motor programs required to complete the motor plan of a complex motor act may depend upon the basal ganglia.

Such a failure to automatically execute learned motor plans could explain both the clinical observations that Parkinsonians cannot undertake sequential motor actions, and the experimental data showing that they cannot execute repetitive learned tracking tasks if essential clues are removed.

\section{REFERENCES}

Angel RW, Alston W, Higgins JR (1970). Control of movement in Parkinson's disease. Brain, 93:1-14.

Brown RG, Marsden CD, Quinn N, Wyke MA (1984) Alterations in cognitive performance and affect-arousal state during fluctuations in motor function in Parkinson's disease. J. Neurol. Neurosurg. Psychiat., in press.

Day BL, Marsden CD (1982) Two strategies for learning a visually guided motor task. Perceptual and Motor Skills, 55:1003-1016.

Denny-Brown D (1968) Clinical symptomatology of diseases of the basal ganglia. In "Handbook" of Clinical Neurology", vol. 6 "Diseases of the Basal Ganglia", pp. 133-211, North-Holland Publishing Company, Amsterdam.

Evarts EV, Trevainen H, Calne DB (1981) Reaction time in Parkinson's disease. Brain, 104:167-186.

Flowers KA (1976) Visual 'closed-loop' and 'open-loop' characteristics of voluntary movement in patients with parkinsonism and intention tremor. Brain, 99:269-310.

Flowers K (1978a) Some frequency response characteristics of parkinsonism on pursuit tracking. Brain, 101:19-34.

Flowers K (1978b) Lack of prediction in the motor behaviour of parkinsonism. Brain, 101:35-52.

Hallett M, Khoshbin S (1980) A physiological mechanism of bradykinesia. Brain 103:301-304.

Heilman KM, Bowers D, Watson RT, Greer M (1976) Reaction times in Parkinson's disease. Arch. Neurol. (Chic), 33:139-140.

Horne DK de L (1973) Sensorimotor control in Parkinsonism. J. Neurol. Neurosurg. Psychiat. 36:742-746.

Keele SW (1968) Movement control in skilled motor performance. Psychol. Bull., 70:387-403.

Kornhuber HH (1971) Motor function of the cerebellum and basal ganglia: the cerebellocortical saccadic (ballistic) clock, the cerebellonuclear hold regulator, and the basal ganglia ramp (voluntary speed smooth movement) generator. Kybernetic, 8:157-162.

Lee RG, Tatton WG (1975) Motor responses to sudden limb displacements in primates with specific CNS lesions and in human patients with motor system disorders. Can. J. Neurol. Sci., 2:285-293.

Lees AJ, Smith E (1983) Cognitive deficits in early stages of Parkinson's disease. Brain, 106:257-270.

Marsden CD (1982) The mysterious motor function of the basal ganglia. Neurology (Minneap), 32:514-539.

Marsden CD (1984) Motor disorders in basal ganglia disease. Human Neurobiology, in press.

Martin JP (1967) "The basal ganglia and posture". Pitman Medical Publishing Company, London.

Mayeux R, Stern Y (1983) Intellectual dysfunction and dementia in Parkinson's disease. In "The Dementias", eds. R Mayeux,WG Rosen. Advances in Neurology, 38:211-227, Raven Press, New York.

Perry RH, Tomlinson BE, Candy JM, Blessed G, Foster JF, Bloxham CA, Perry ER (1983) Cortical cholinergic deficit in mentally impaired parkinsonian patients. Lancet, 2:789-790.

Poirier LJ, Pechadre JC, Larochelle L, Dankova J, Boucher R (1975) Stereotaxic lesions and movement disorders in monkeys. In "Advances in Neurology, 10, eds. BS Meldrum, CD Marsden, pp. 5-22, Raven Press, New York.

Quinn N, Parkes JD, Marsden CD (1982) Complicated response fluctuations in Parkinson's disease: Response to intravenous infusion of levodopa. Lancet, 2:412-415.

Rothwell JC, Obeso JA, Traub MM, Marsden CD (1983) The behaviour of the long-latency stretch reflex in patients with Parkinson's disease. J. Neurol. Neurosurg. Psychiat, 46:35-44. 
Rothwell JC, Traub MM, Day BL, Obeso JA, Thomas PK, Marsden CD (1982) Manual motor performance in a deafferented man. Brain, 105:515-542.

Ruberg M, Ploska A, Javoy-Agid F, Agid Y (1982) Muscarinic binding and choline acetyltransferase activity in parkinsonian subjects with reference to dementia. Brain Res., 232:129-133.

Schwab RS, Talland GA (1964) Performance with multiple sets in Parkinson's disease. Neurology (Minneap), 9:65-72.

Schwab RS, Chafetz ME, Walker S (1954) Control of two simultaneous voluntary motor acts in normals and parkinsonism. Arch. Neurol., $72: 591-598$
Schwab RS, England AC. Peterson E (1959) Akinesia in Parkinson's disease. Neurology (Minneap), 9:65-72.

Stern Y, Mayeux R, Rosen J, Ilson J (1982) Perceptual motor dysfunction in Parkinson's disease: A deficit in sequential and predictive voluntary movement. J. Neurol. Neurosurg. Psychiat. 46:145-151.

Tatton WG, Lee RG (1975) Evidence for abnormal long-loop reflexes in rigid Parkinsonian patients. Brain Res., 100:671-676.

Wilson SAK (1925) Disorders of motility and muscle tone, with special reference to the striatum. Lancet, 2:1-53, and 169.215 and 268. 